\title{
焼結タングステン細線の高温クリープに及ぼす 2 次再結晶粒形態の影響十
}

\author{
田上耕司 緒方博之师 \\ 九州工業大学工学部物質工学科
}

J. Japan Inst. Metals, Vol. 63, No. 5 (1999), pp. 585-588

Papers from JIM Fall Meeting (1998)

\section{Morphological Effect of Secondary Recrystallized Grains on High-Temperature Creep of $P / M$ Tungsten Fine Wires}

\author{
Koji Tanoue and Hiroyuki Ogata ${ }^{\dagger \dagger}$
}

\begin{abstract}
Department of Materials Science and Engineering, Faculty of Engineering, Kyushu Institute of Technology, Kitakyushu $804-8550$
\end{abstract}

\begin{abstract}
It is investigated how the morphological change of secondary recrystallized grains grown in powder metallurgy tungsten fine wires has an effect on creep at high temperatures after it is quantitatively estimated. The quantitative treatment of the grain morphology is possible by using $f_{1}$ as the representative one of the grain shape parameters. The optimum interlocked grain structure is defined as the grain morphology in which the grain aspect ratio is minimized under the condition that the area of grain boundaries does not increase drastically. The hightemperature creep can then be characterized by the index $\Delta I\left(=f_{1}-f_{1}^{0}\right)$ which indicates the degree of deviation from the optimum interlocking of grains which is designated by $f_{2}^{0}$. The region of power law creep in the deformation mechanism maps is minimized at $\Delta I=0$ at which the grains are most favourably interlocked, being extended as $\Delta I$ deviates from $\Delta I=0$. It is considered that the deformation in the region is strongly influenced by grain boundary sliding, being further done by grain boundary cavitation with an increase in $\Delta I$ at $\Delta I>0$.
\end{abstract}

(Received November 27, 1998; In Finai Form February 10, 1999)

Keywords: bubble, interlocking, non-sag grain structure, deformation mechanism map, activation energy for steady state creep, grain boundary sliding, grain boundary cavitation, doped wire

\section{I 。緒言}

結晶粒が等方的な場合には，結晶粒に起因する材料の物性 の変化はほぼ平均結晶粒径に関係付けることができる。しか し，ドープタングステン細線の 2 次再結晶粒のようにアス ペクト比 $R$ が10 130 と非常に大きく(1)，粒が互いに入り組 も(interlocked)ような場合にはアスペクト比，材料中の全 粒界面積やインターロツクの程度などによって特徽付けられ る組織，いわ功る粒の形熊が重要となる。粒のアスペクト比 が $R<30$ に小さなり粒がインターロックされるにつれて 粒界面積が増加し，粒界すべりや粒界キャビテーションの発 生頻度も増加するためクリープ歪及る増加する(2)(3)。一方 で，粒のアスペクト比が大きくなり粗大結晶粒に近付けば粒 界面積も減少するためクリープ歪みが減少すると考克られ る.しかし，実際には $R>30$ では $R$ の増加につれてクリプ歪みが逆に增加する結果が得られ，これは粒界すべりの抵 抗となっていた粒の起伏が小さくなるためと考えられてい

† 1998年9月29日日本金属学会秋期大会に括いて発表

什九州工業大学大学院生, 現在: 東芝ライテック蛛)(Graduate Student, Kyushu Institute of Technology. Present address: Toshiba Lighting \& Technology Corp.)
る(4)。したがって，高温クリープ歪みを極力抑えるためとは 適度にインターロックした粒の形態が選択されなければなら ない、しかし，粒のインターロックや形態についての定義が あい屯いで定量的な取り报いがなされていないためそれらと 高温クリープとの関連性が定性的にしか把握されていない.

ドープタングステン細線に掠ける2次再結晶粒のような 特烘な粒の形態は線材中化数多く存在する微小なバブルによ って発達させられる。焼結前に添加された少量の $\mathrm{K}, \mathrm{Al}, \mathrm{Si}$ (残留質量濃度約 $100 \mathrm{ppm}$ 以下) は焼結時には酸化物として インゴット中に存在し，その後水素気流中で還元されて加工 工程中に微細に分散しながら，線极軸方向に並んだ微小なバ ブルを形成する。そして，バブルが軸に直角な方向への粒の 成長を抑制しその効果もバブルの分散状態によって異なるた め，軸方向に長く伸び，かつインターロックした2次再結 晶粒が出現する(2). したがって，バブルの大きさ，数执よび その分散状態が粒の形態を決定する最大の要因となる。他の 要因としては，1次再結晶粒と 2 次再結晶核相互の方位関係 によってほぼ決定される 2 次再結晶粒の成長の駆動力が考 えられる(1)(5)。このことは最終的に残存する駆動力の大きな 2 次再結晶粒の数や形は粒成長のために与克られる時間によ って左右されるといら意味で，粒の形態が昇温速度に強く依 存する(1)(2)ことからも明らかである. 
とこで本研究においては，種々の昇温速度により变化させ た粒の形態の定量化を試みここれらと高温クリープを特徵付 ける変形機構図や定常クリープの活性化エネルギーなどがど のように関係付忊られるかを明らかたする。

\section{II. 実 験 方 法}

実験に使用した材料は公称純度が $99.96 \%$ 以上のドープタ ングステン細線 $(\phi 0.13 \mathrm{~mm})$ でる。添加元素としてのK, $\mathrm{Al}, \mathrm{Si}$ の残留濃度はそれぞれ0.0075，<0.001，0.001土0.0003 mass\%であった。試料の熱処理は全て $<10^{-5} \mathrm{~Pa} の$ 真空中 に护ける直流通電加熱方式によって行った。結晶粒の形状を 変化させるため，䍙温速度を $0.2 \sim 985 \mathrm{~K} / \mathrm{s}$ の範囲内で変化 させ $2660 \mathrm{~K}$ まで昇温し，同温度で $300 \mathrm{~s}$ 間保持して完全 2 次再結晶化させた，そして，線材を常温硬化性樹脂に埋め込 又，割断面扣よび線䄪中心部を通る縌断面を研磨後，30g $\mathrm{K}_{3} \mathrm{Fe}(\mathrm{CN})_{6}+2 \mathrm{~g} \mathrm{NaOH}+100 \mathrm{~cm}^{3} \mathrm{H}_{2} \mathrm{O}$ の腐食液で粒界を現 出させた。縦断面では 2 次元的な粒のアスペクト比の測定 を行い，割断面では線材軸方向に約 $20 \mu \mathrm{m}$ 間隔で $500 \mu \mathrm{m}$ にわたって 2 次元的な結晶粒の形状を測定して 3 次元画像 解析装置を用いて粒の立体像を組み立てた。この立体像から 粒の表面積 $S$ 測定して長さ約 $500 \mu \mathrm{m}$ の試料の体積 $V$ 中 に存在する全粒界面積を試料の単位体積当りの粒界面積 $S / V$ として求めた。さらに各割断面 $i$ お汓る粒の断面積 $A_{\mathrm{i}}$ と周 長 $Q_{\mathrm{i}}$ 加 $A_{\mathrm{i}}$ と形状因子 $F_{\mathrm{i}}\left(=4 \pi A_{\mathrm{i}} / Q_{\mathrm{i}}^{2}\right)$ を線材軸方向飞沿 って求めた。ここで $F_{\mathrm{i}}$ は周長 $Q_{\mathrm{i}}$ を持つ真円の面積 $A_{\mathrm{i}}^{0}$ に対 する $A_{\mathrm{i}}$ の割合 $A_{\mathrm{i}} / A_{1}^{0}$ として求められるので, $F<1 て ゙ め り$, $F$ が1に近づくつれて真円に近くなる。 そして，得られ た $A$ と $F$ が軸方向へどのように変化するか子示すパラメー ター $f_{1} \sim f_{3}$ 当次式によって導出した。

$$
\begin{aligned}
& f_{1}=\frac{1}{N} \sum_{\mathrm{j}=1}^{N} \frac{\sum_{i=2}^{n}\left|A_{\mathrm{ji}}-A_{\mathrm{j}(\mathrm{i}-1)}\right| / \sum_{i=1}^{n} A_{\mathrm{ji}}}{n-1} \\
& f_{2}=(\bar{F})=\frac{1}{N} \sum_{j=1}^{N} \frac{\sum_{i=1}^{n} F_{\mathrm{ji}}}{n}
\end{aligned}
$$

\section{Heating Rate, $R_{H} / \mathrm{Ks}^{-1}$}

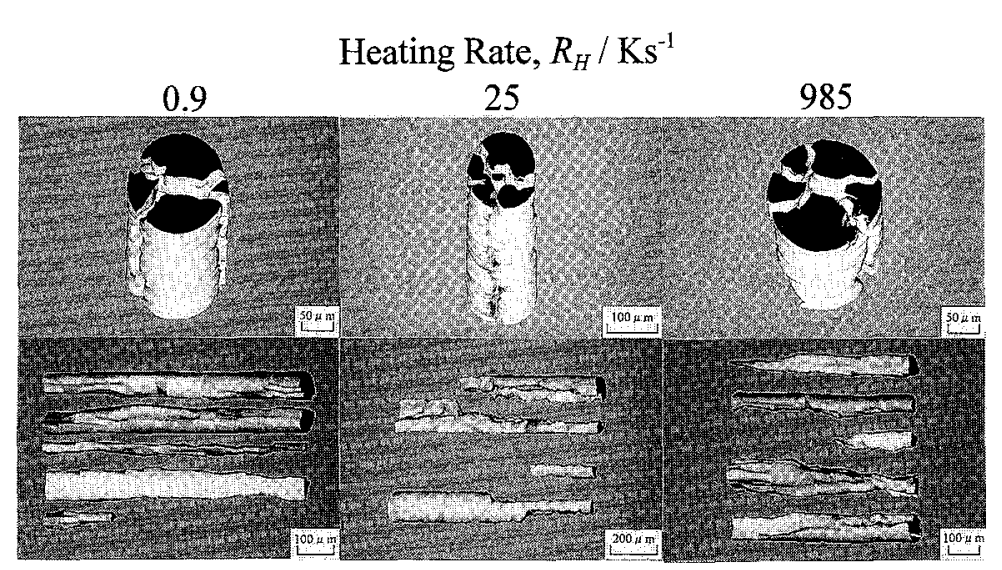

Fig. 1 Stereoscopic views of secondary recrystallized grains constructed by a three-dimensional image analyzer for doped tungsten wire annealed

for $300 \mathrm{~s}$ at $2660 \mathrm{~K}$ after heating at each rate.

$$
f_{3}=\frac{1}{N} \sum_{j=1}^{N} \frac{\sum_{i=2}^{n}\left|F_{\mathrm{ji}}-F_{\mathrm{j}(\mathrm{i}-1)}\right|}{n=1}
$$

ここで $N(=4 \sim 8)$ は測定された結晶粒の個数， $A_{\mathrm{i}}$ と $F_{\mathrm{i}}$ はそ れぞれ $i$ 番目の割断面に拈ける粒の断面穦と形状因子であ り，nは線材軸に沿った全割断面数で長さが $500 \mu \mathrm{m}$ の測定 では $n=26$ となる. $f_{1}$ と $f_{3}$ はそれぞれ $A$ と $F$ の軸方向への 変化を示寸折れ線の長さに比例するものであり， $f_{2}$ は $F$ の 軸方向八の平均值 $\bar{F}$ 意味している(2).

クリープ試験は自動荷重一歪み制御装置を備えたインス卜 ロン型引張試験機によって行った。ゲージ長さを $50 \mathrm{~mm}$ と して試験機にセットした試験片に通電し, 粒形状の測定の場 合と同様にして 2 次再結晶化させた。その後引き続いて， 2075 2975 K の各温度でクリープ試験を行った。 委た，定 常クリープの活性化エネルギー $H$ を求めるため, 定常クリ 一プの漂究中央で応力扣よび昷度急変試験(6)を行って $H$ を 次式によって求めた。

$H=k T^{2}\left[(\partial \ln \dot{\gamma} / \partial T)_{\tau}+(\partial \ln \dot{\gamma} / \partial \tau)_{\mathrm{T}}\left(\tau_{\mathrm{i}} / G\right)(\mathrm{d} G / \mathrm{d} T)\right]$ ここで $k$ はボルッマン定数, Tは絶対温度, $\tau(=\sigma / 2)$ は剪 断応力, $\gamma$ は剪断歪速度, $\tau_{\mathrm{i}}$ は内部応力， $G$ は剛性率であ る。な特，直流通電加熱方式によるクリープ変形中の試験温 度の保持, 粒の 3 次元的形状の湘定方法や $f_{1} \sim f_{3}$ の特致な ぞの詳細についてい前報(2)(4)(7)に記した通りである。

\section{III. 実験結果および考察}

\section{1. 粒形態の定量的評価}

昇温速度を变化させて得ら机た 2 次再結晶粒の形状を 3 次元的に測定し，粒のイメージ像を組み立てた。その結果を Fig. 1 亿示す。昇温速度が増加するにつれて，粒の形状は 複雑になり軸方向の長さむ減少していることが分かる。この ような各粒のイメージ像から粒の断面積 $A$ と形状因子 $F$ を 求め式 (1) （3）で定義される粒の形状任関するパラג一 タ一 $f_{1} \sim f_{3}$ を得た。 $f_{1}$ と $f_{3}$ が昇温速度の上昇につ机てほぼ 同様の增加を示す一方， $f_{2}$ は泀とんど一定であったのでここ では $f_{1}$ と $f_{3}$ を粒の形状に関するパラメーターとして用いた。 $f_{2}$ が昇温速度によらず汪とんど一定であるといらことは，

Fig.1からも明らかなよらに，各割断面に和ける粒の形状は ほぼ一定であることを意味している(2).Fig. 2 には $f_{1}$ と $f_{3}$

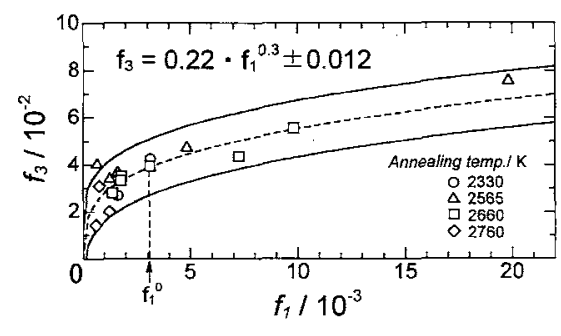

Fig. 2 The relation between the grain shape parameters $f_{1}$ and $f_{3}$ which increase as the grains are interlocked. 


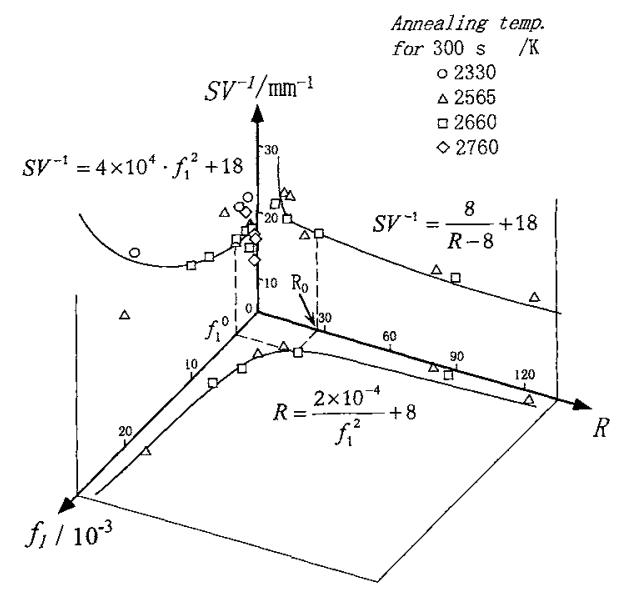

Fig. 3 The relation between the grain shape parameter $f_{1}$, the grain aspect ratio $R$ and the area of grain boundaries per unit volume of a specimen $S / V$. The critical value $R_{0}$ indicates the minimum grain aspect ratio at which $S / V$ begins to increase with a decrease in $R$.

との関係を，末たFig. 3 には $f_{1}$ と粒界面積 $S / V$ および粒の

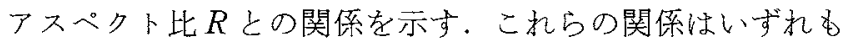
図中の実験式で示されるように互いに関連し， $f_{1}, f_{3}, S / V, R$ のパラメーターの5ちいずれか1つが決定されれば昇温速 度によらず全てがほぼ決定される。つまりこのことは実験䛊 美の範囲内で粒の形態が決定されることを意味している。た だしこれらの関係は本実験に用いた材料のみに有効であり， 加工工程や添加剤の濃度が変われば当然変わってくるである らといらことに留意しなければならない，い李，粒の形態を 定量的に取り报らため4つのパラメーターを的で代表させ て，粒形態指数として定義して用いることにする．Fig. 1 に 示されるよらな粒を持つ試料を用いてクリープ試験を行い， 得られた最小クリープ速度 $\dot{\varepsilon}_{\mathrm{m}}$ と剛性率 $G^{(8)}$ で規格化した応 力とを $f_{1}$ ともに示したのが Fig. 4 である. $2975 \mathrm{~K}$ 末満 の温度ではいずれるべ乗則クリープであり，応力指数 $n_{\mathrm{s}}$ は低応力側で $n_{\mathrm{s} 1}=2 \sim 5 \mathrm{~K}$, 高応力側で $n_{\mathrm{s} 2}=5 \sim \infty$ K変化 する一方で， $2975 \mathrm{~K}$ では $n_{\S}=1$ の拡散クリープの特徵を示 している。また， $\dot{\varepsilon}_{\mathrm{m}}$ を同一の温度と応力で比較した場合， その汪とんどが $f_{1}=3.1 \times 10^{-3}$ のとき小さい値を示している

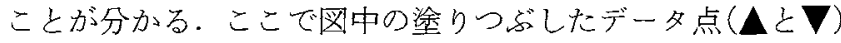
はそれぞれ $2330 \mathrm{~K}$ と $2975 \mathrm{~K}$ の各温度に乱りる $\sigma=30 \mathrm{MPa}$ の点であり，2,3のクリープ特性の粒形態依存性が調べられ た条件を示している。また，同一応力でありながらこれらの 点には横軸に沿って差が生じているのは，Gの温度依存性 によるすのである。

\section{2. インターロック粒組織の最適状態指数 $I_{\mathrm{m}}$}

昇温速度の增加による粒組織の变化は，Fig. 5 飞模式 的に示されているよ5飞，粒形態指数 $f_{1}$ によって定量的に 取り报うことができた。通常，白熱球が $3.6 \times 10^{6} \mathrm{~s}$ 以上の 耐用寿命を達成すをるためにはクリープ速度は $10^{-9} \mathrm{~s}^{-1}$ 以下 でなければならないといわれている(9)ので，クリープ歪みは 可能な限り抑制されることが望泉しい， $f_{1}$ が増加し粒の形状 が複雑になるにつれて，粒界面積が増加し粒界キャビテーシ ョンや粒界すべりが起こりやすくなるため施は増加す る(2)(4). 一万で， $f_{1}$ が減少し粒が粗大になりすぎると粒界の 起伏が小さくなるため，西るいは伸びた粒の両端での入り組
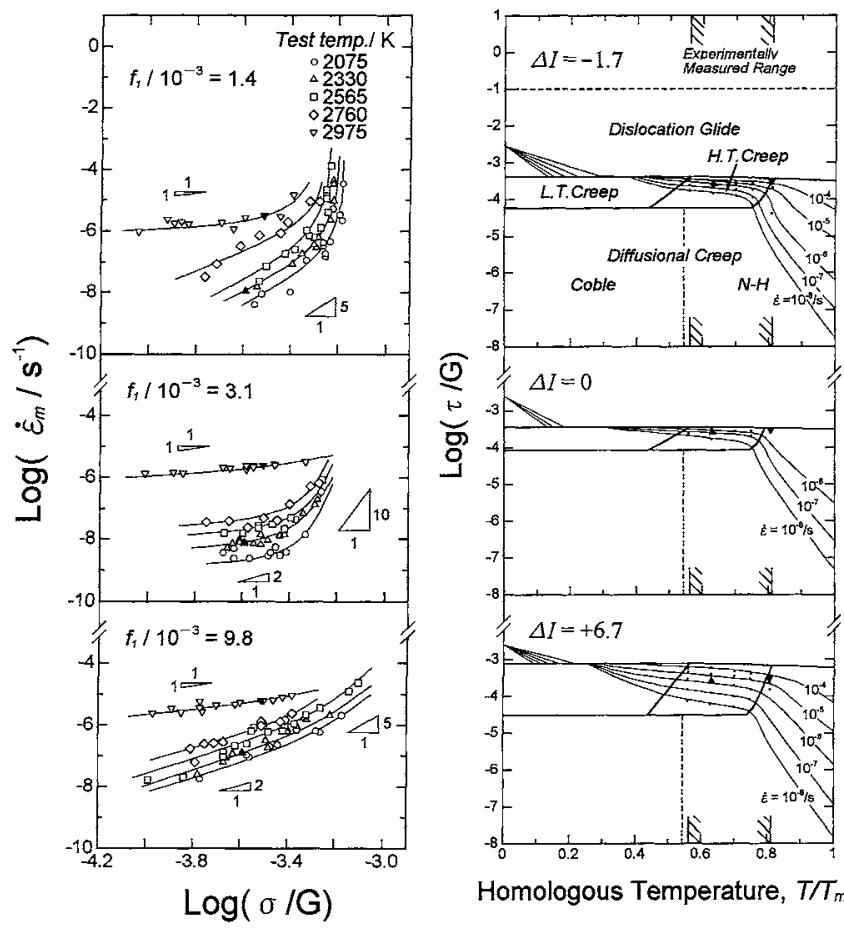

Homologous Temperature, $T / T_{m}$

Fig. 4 Logarithmic plot of the minimum creep rate against the modulus corrected stress for the doped wires with the different grain morphologies which are characterized by $f_{1}$.

Fig. 6 Deformation mechanism maps for the doped tungsten wires with the different degrees of interlocking which is characterized by $\Delta I$.

\section{are characterized by $f_{1}$}

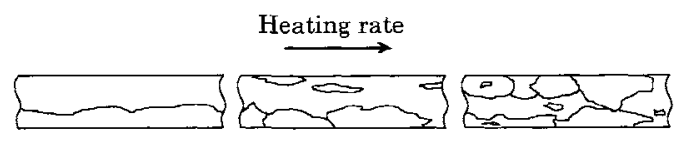

$f_{1} / 10^{-3}=$ $a_{1} \cdots<\cdots a_{i} \cdots<\cdots a_{u}$

$\mathrm{I}_{\mathrm{m}}\left(=\mathrm{f}_{\mathrm{I}} \mathrm{o} / 10^{-3}\right)=$

$\Delta \mathrm{I}=\left(\mathrm{f}_{1}-\mathrm{f}_{1}^{0}\right) / 10^{-3}=\left(\mathrm{a}_{1}-\mathrm{a}_{\mathrm{j}}\right)<0$

Fig. 5 Schematic representation of the change of the grain morphology with an increase in heating rate and its charac terization by using the grain shape parameter $f_{1}$. The indices $I_{\mathrm{m}}$ and $\Delta I$ indicate the optimum interlocked grain structure, which is characterized by $f_{1}^{0}$ (or $R_{0}$ ) in Fig. 3 , and the degree of deviation from $I_{\mathrm{m}}$, respectively.

みが小さくなって線材を横断しての粒界すべりが容易になる

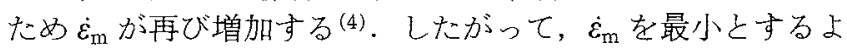
らな最啇なインターロック状態にある粒の形態を定量的に求 める必要がある。しかし，粒には「粒虫大粗大化してアスペク 卜比も大きく，粒界面積はなるべく小さい方が望李しい」と 「粒のアスペクト比は小さく，粒は複雑でなるべくインター Fックするほらが望京しい」といらよう飞互い相反する条 件が要求される。そこでここではFig. 3 に䊉いて，インタ 一ロック粒組織の最適な状態として「粒界面積 $S / V$ の急激 な増加を伴わない最小のアスペクト比 $R_{0}$ を有する粒の形 態」を定義した。 そして $R_{0}$ に対応する $f_{1}^{0}$ を，Fig. 5 K示寸 ように最適状態指数 $I_{\mathrm{m}}$ とし，尔たその状態からのズレの度 


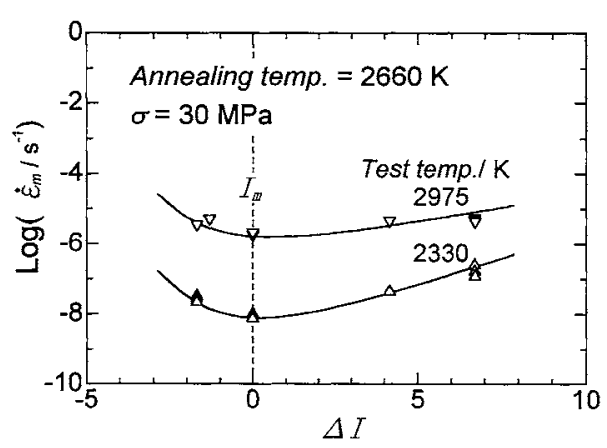

Fig. 7 Variation of the minimum creep rate $\dot{\varepsilon}_{\mathrm{m}}$ with $\Delta I$.

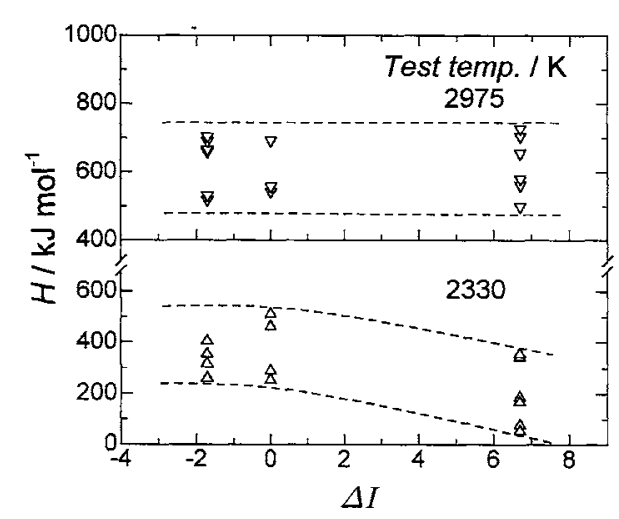

Fig. 8 Variation of the activation energy for steady state creep $H$ with $\Delta I$.

合いを $\Delta I\left(=f_{1}-f_{1}^{0}\right)$ として用いてクリープ特性と粒形態の 変化を関連付けた。つま，高温クリープ歪み抑制のための 粒のインターロックは $\Delta I=0$ で最適の状態であり， $\Delta I$ が正 と負にズレるにつれて, 粒同士の入り組みとそれからの解放 がそれぞれ増加することを意味している。

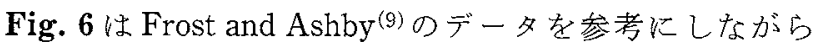
Fig. 4 を変形機構図に書き直したものである。Fig. 4 の郎 加々その等高線肪得られ，応力指数 $n_{\mathrm{s}}$ の逆数 $1 / n_{\mathrm{s}}$ (歪速度感 受性指数) は応力軸に沿った等高線の間隔を決定している。 そして，べキ乗則クリープの領域は $\Delta I=0$ で最も狭くなっ ており， $\Delta I=0$ からズレるにつれて正負いずれにおいても搪 大していることが分かる。図中炕とマで示される条件でク リープ試験和よび応力-温度急变試験を行って $\dot{\varepsilon}_{\mathrm{m}}$ と $H$ 求

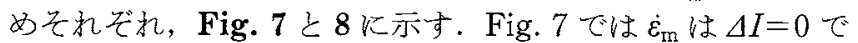

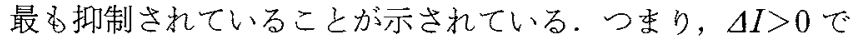
はいずれの温度でも粒界キャビテーションが多く観察されて いる(3)ことから，こ机は $\Delta I$ の増加に伴って応力軸と直角に 近い大きな角度で交わる粒界，あるいは粒界 3 重点の数が 増加して粒界キャビテーションの頻度を增加させるために $\dot{\varepsilon}_{\mathrm{m}}$ が増加すると考克られる。李た， $\Delta I<0$ ではその逆で粒 界キャビテーションは起こりにくく， $\Delta I$ の減少につれて粒 界の起伏が減少し，粒界すべりが起こりやすくなるため(4) 考它られる.このことはFig. 8 K示される $H$ れ $\Delta I$ に対し ての依存性加古支持される。.Fig. 8 亿和ける，2975 Kの 条件 (Fig. 4 と6 中の印)では $H$ は $\Delta I$ に忹とんど依存せず $H=620 \pm 120 \mathrm{~kJ} \mathrm{~mol}^{-1}$ となった。この値はタングステンの 自己拡散の活性化エネルギー $H_{\mathrm{L}}$ の $H_{\mathrm{L}}=640 \mathrm{~kJ} \mathrm{~mol}^{-1}$ (10) と
ほぼ一致するので， $n_{\mathrm{s}}=1$ であることも考慮すればこの変形 条件は拡散クリープ領域に位置すると思方れる。一方， $2330 \mathrm{~K}$ の条件(Fig. 4 と6 中の山印)では $H$ は $H_{\mathrm{L}}$ と一致せ

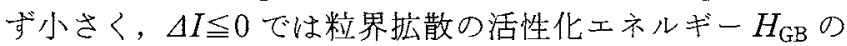
$H_{\mathrm{GB}}=390 \mathrm{~kJ} \mathrm{~mol}^{-1}(10)$ K近い值を与えて和り，さらに $\Delta I>0$ になるとパイエルス機構に対しての活性化エネルギー $H_{\mathrm{PN}}$ の $H_{\mathrm{PN}}=150-200 \mathrm{~kJ} \mathrm{~mol}^{-1}$ (11)にまで減少している. $\Delta I>0$ の粒では $H$ に及佂す粒界キャビテーションの影響る また考慮されなけ机ばならない，2975 Kでは温度が高いた

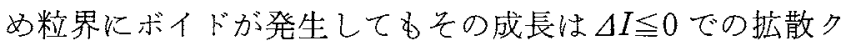
リープの場合と同様汇粒内拡散によって律速されていると思 われる。しかし，2330 K ではいずれの粒形態に和いても粒 界拡散によって律速される粒界すべりが支配的であるが， $\Delta I>0$ に执いて粒界キャビテーションの影響が強くなると， 粒界ボイドの成長がそれを取り囲さ粒のマトリックスに数け る变形によって律速される，いわゆる拘束されたボイドの成 長 (constrained cavity growth) 機構 ${ }^{(12)}$ にってクリープが 律速されるため $H$ が $H_{\mathrm{PN}}$ 委で減少すると考古られる(2)(13).

\section{N. 結 論}

焼結タングステン細線中に発達する 2 次再結晶粒の形態 を定量化し，それらの変化が高温クリープにどのよらな影響 を及隹すかについて調べた。、以下に得られた結果を要約する。

(1) 2 次再結晶粒の形態を粒形状に関するパラメーターの 1つ $f_{1}$ で代表させることにより定量的に表すことがでさる。

(2) 粒の最適なインターロック状態にある組織を「粒界面 積の急激な增加を示さない最小のアスペクト比を有する粒の 形態」と定義し，その状態 $f_{1}^{0}$ かららのズレ指数 $\Delta I\left(=f_{1}-f_{0}^{1}\right)$ によって高温クりープを特徵付けることができる。

(3) 変形機構図中のべキ乗則クリープ領域は粒が最適にイ ンターロックされている状態の $\Delta I=0$ で最も狭く，それか らズレるにつれて拡大した。また，同領域の変形は粒界すべ りによって強く影響を受け， $\Delta I>0$ では $\Delta I か ゙$ が加するにつ れてさらに粒界乎ャビテーションによる影響が加わると思わ れる。

\section{文献}

（1）陳 樹繁，米田博之，藤井浩二，田上耕司，松田日出彦：日 本金属学会誌, 53(1989), 1198 .

（2）田上耕司，渡邊和弘，松田日出彦：日本金属学会誌， $\mathbf{5 9}(1995), 1230$.

(3) K. Tanoue, Y. Ohtani and H. Matsuda: Mater. Trans., JIM, 34(1993), 1177.

(4) K. Tanoue: Met. Mater. Trans., 29A(1998), 519.

(5) Y. Ohba: Acta Met., 34(1986), 1329.

(6) H. Conrad and H. Wiedersich: Acta Met., 8(1960), 128

（7）田上耕司, 米田博之, 藤井浩二, 松田日出彦：日本金属学会 誌, 54(1990), 991.

(8) S. W. H. Yih and C. T. Wang: Tungsten, Plenum Press, New York, (1979), p. 270.

(9) H. J. Frost and M. F. Ashby: Rate Processes in Plastic Deformation of Materials, Ed. by J. C. M. Li and A. K. Mukherjee, ASM, (1975), p. 70.

(10) S. L. Robinson and O. D. Sherby: Acta Met., 17(1969), 109.

(11) H. Conrad: The Relation Between the Structure and Mechanical Properties of Metals, HMSO, London, (1963), p. 475.

(12) A. C. F. Cocks and M. F. Ashby: Progress in Materials Science, Vol. 27, Pergamon Press, New York, (1982), p. 189.

(13) K. Tanoue and H. Matsuda: Scripta Met. et Mater., 33 (1995), 1469. 